\title{
STRATEGIC AND OPERATIONAL FOCUS OF HEALTH PREVENTION IN PRIVATE AND PUBLIC SECTOR ORGANISATIONS
}

\author{
Juliane Meixner ${ }^{1}$
}

\begin{abstract}
In this paper, with a view to the high levels of absence due to sickness and presenteeism, it is explored how management and team leadership can be integrated on a more sustained basis in health prevention. Private sector enterprises on one hand, and organisations in the public sector, on the other, pursue and prioritise in this aspect different approaches, which are traceable to their different traditions. Specifically in Germany in the public sector, the principle of due care has had a long tradition that grows out of social responsibility, which contrasts with the perspective of commercial enterprises that emphasises the economic aspect. The study undertakes to determine the particular strengths of each of the sectors and to demonstrate their different approaches. The examination refers in its methodology to qualitative social research. In the systemically structured survey design, Seventy six experts were approached with questions concerning different aspects such as corporate culture, business processes, organisational integration, qualification, risk assessments, and concrete actions in health prevention. Complementary to the expert survey, documents such as corporate guidelines and policies, management tools, results from risk assessments and employee surveys or quality offensives were referred to. This analysis supplied insights on how the declared health prevention policies in an organisation can be effectively implemented at the strategic and operational level in corporate culture and leadership culture with a long-term continuity, and which organisational prerequisites in the corporate hierarchy and corporate decision making and business processes may reinforce and sustain successful implementation of health prevention. Of particular importance in the process is operative management. For the sake of effective team involvement in own and team-specific health prevention, an eight-stage team feedback was devised, which includes elements of self-reflection and perception by others in an iteratively structured process.
\end{abstract}

JEL Classification Numbers: M14, M59, L20, DOI: https://doi.org/10.12955/peb.v2.256

Keywords: Health management, occupational health \& safety (OHS), corporate culture, leadership culture, health control, risk assessment, work climate

\section{Introduction}

Health prevention is not just a matter of efficient operation in economic terms but is also about the principle of corporate social responsibility (CSR, McWilliams, et al. 1999) and a humane working environment (Ergonomics, DIN EN ISO 6385:2016). Further, in a labor market controlled by job seekers, a concise health concept boosts the appeal of a company as an employer (IFBG, 2020). Applicable law though does not leave these activities to the companies' discretion but promotes with regulations a healthy and humane working environment (humanisation of the work environment). For example, the German Occupational Safety Act (ASiG) imposes an obligation on the private and public sectors to appoint company physicians and dedicated professionals in matters of occupational health \& safety (ASiG, 1973). This creates an organisational and structural prerequisite that consistently shapes business processes. These professionals boost the organisational units in charge of occupational safety and accident prevention. The German Labour Protection Act (ArbSchG, 1996) imposes in its Section 4 (3) an obligation on employers to integrate into work processes insights from industrial/work science and ergonomics. The general guidelines for this are provided in DIN EN ISO 26800:2011 »Ergonomics - General approach, principles and concepts« and DIN EN ISO 6385:2016»Ergonomics principles in the design of work systems «. The German Ordinance on Industrial Health and Safety demands in its current version that hazards posed by mental strains and stresses are dealt with consequently and places responsibility for these activities on the management (Schmid \& Pircher Verdorfer; Wilrich, 2015a; Wilrich, 2015b). The management and managers are required to assess the hazards their reporting employees are exposed to, take protective action and thus reduce the risks. For that, the management must create the structural prerequisites in which executive managers are then able to act within the scope of their assigned responsibilities (Uhle \& Treier, 2019). Badura (2017) attaches a high prevention potential to the work atmosphere and concludes that the actual key morbid factor is not stressed in itself but the lack of emotional attachment to the enterprise, activities that make no apparent sense, wrongly set targets, and non-recognition of work performance. In order to counter such negative developments, involvement is needed, particularly of the management (ZFW, 2016).

According to DIN EN ISO 6385:2016, work stress is the "entirety of the external conditions and requirements in the work system that affect a person's physiological and/or psychological state". To gain insights into work stresses, surveys on work satisfaction and hazard potential have become the tool

\footnotetext{
${ }^{1}$ Juliane Meixner, PhD Student, Faculty of Management, Comenius University in Bratislava, Slovakia,
} meixner3@uniba.sk 
of choice (Pfaff et al., 2020). In a standardised questionnaire, items for hazard assessment are grouped according to their importance and urgency and presented to the respondents for assessment of the (individual) stresses they are exposed to. In the next open-ended part of such surveys, employees may detail situational particularities and expose individual and team-specific stress factors.

Empirically, the overall level of participation in such surveys in an organisation ranges approximately from $30 \%$ to about $50 \%$ of the workforce (Meixner \& Meixner, 2019a). However, this extent of participation varies between organisational units on a wide scale. This study aims to clarify what these differences are traceable to and what targeted measures can be taken in this particular regard. Another phenomenon has been explored in the present analysis: in regularly repeated surveys for the hazard analysis, there appears a high variance in participation (Meixner \& Meixner, 2019b). A large part of the respondents is not available for a follow-up survey. The aim is to identify the options to shape the structural and executive aspects of such surveys to increase their appeal and participation levels. As a particularly important factor in the process, the impact has been identified on executive managers.

\section{Literature review}

Today, corporate health management is deemed in commercial enterprises a core part of their corporate strategies. Almost ten percent of companies already have health-related arrangements and management guidelines integrated into their corporate culture. Other companies are planning to implement and develop a corporate health management system (IFBG, 2020). This is because health now is treated both in the private and professional spheres as a value that must be preserved and promoted. This is now about salutogenesis as opposed to the earlier pathogenesis. While pathogenesis focuses on the causes of and emergence of diseases, salutogenesis deals with the factors that aid health in order to sustain and promote health. In contrast pathogenesis focuses on risk minimisation as regards diseases (Antonovsky, 1997; Antonovsky, 1993). This development has been driving a paradigm change in health prevention and has been nurturing new occupational health \& safety approaches. Nowadays, the design of healthy work in a healthy work environment is increasingly emphasised (Initiative Gesundheit und Arbeit, 2015). This designing process with a more sustained effect necessitates a redefinition of strategic alignment of organisational structures and process flows. Health becomes an integral part of corporate philosophy. This is summarily referred to as health management (Ghadiri \& Peters, 2020; Uhle \& Treier, 2019; Ulich \& Wülser, 2018).

While occupational health \& safety mainly focuses on combatting overload and occupational illnesses, health prevention goes one step further. Health prevention reinforces health resources (Simmel \& Graßl, 2020; Homberg, 2016). The World Health Organization defines health (1946) as "[...]a state of complete physical, mental and social wellbeing and not merely the absence of disease or infirmity". Well-being of employees thus is stressed out as an important health factor. Within the work environment context, this has also led to a more prominent emphasis on work satisfaction. The aim is to promote both physical and mental health (Homberg, 2016; Matyssek, 2012). In this regard, it would be overly reductive to interpret the aim of health prevention as a means to reduce days of absence. Health management accordingly goes further and promotes a healthy work environment. Thus put into perspective, statistics of days of absence can be one aspect at best within the overall context of health prevention (Kloimüller, 2016). Accordingly to this, the return talks should also be seen as part of a more comprehensive hazard assessment. In such return talks, the causes of illnesses in the work environment should be analyzed to counter these (Berg, 2019; Richter \& Geis, 2019; Giesert et al., 2016).

The hazard assessment is a core aspect in health management and thus also a key part of preventive healthcare. The hazard analysis includes the systematic assessment of the physical and mental stresses, and hazards employees are exposed to in their work (Pfaff et al., 2020; Neuner, 2019). Such analysis has a systemic scope that comprises the entire work system with its components and their properties and how they relate to each other. The German Federal Institute for Occupational Safety and Health lists on this ten different hazard factors with many more subgroups. The assessment of health hazards has in the technical sphere (such as work tool design) and for physiological factors (such as lighting, ambient temperature, dust) a long tradition (Bundesanstalt für Arbeitsschutz und Arbeitsmedizin, 2021). However, the priorities for morbid factors and variables that pose health hazards have been shifting towards psychological hazard factors and thus away from industrial manufacturing and in the direction of white-collar jobs in trade and commercial and also in the services sector. This group of psychological hazards is represented by the hazard factors nine and ten as defined by the Federal Institute for 
Occupational Safety and Health, with subcriteria such as time pressure, working hours, night-time work, process flows at work, social contacts, leadership behaviour, conflicts as well as conditions in the workplace and in the work environment. These criteria define the level of difficulty of a task and map out the mental stresses. However, these stresses subjectively are experienced differently by each individual (Neuner, 2019). Given the subjective assessment of what makes a stress situation, this results in different levels of stress between individuals. This makes interpretation of the results of a hazard assessment more difficult, such as in representative surveys or surveys with the whole statistical population, which are used for hazard assessment of the psychological hazard factors (Treier, 2019).

Changing work conditions and the fast pace of change in the work environment have been a force that keeps the health risk situation of employees in a state of constant flux, adds to requirements and stresses, and affects the risk factors for the health of the workforce. The German Occupational Safety Act (ASiG) that entered into force in its first version in 1973 demands that a healthy work environment be created. Under the Occupational Safety Act, "the employer [...] must appoint in accordance with the provisions of this law company physicians and dedicated professionals in matters of occupational safety [...]" (§ $1 \mathrm{ASiG})$.

Of note in this context are the changes in priorities from the 1970s up to the present (Kleinöder et al., 2019). While in the last century, the key emphasis was still on the physiological design of the workplace, today, this has also been extended by the topic of work processes that make sense (Hardering, 2020). This is an unmistakable shift from researching and designing physiological stress factors to psychological ones (Badura et al., 2020).

The lawmakers thus saw in 2013 the need due to the massive increase in mental illnesses to prepare a draft act of law for a systematic hazard assessment. The development mentioned has been confirmed by many studies. For instance, according to "Stressreport" (Bundesanstalt für Arbeitsschutz und Arbeitsmedizin, 2020), 38\% of employees experienced in 2018 an increase in stress over past 2 years. This figure correlates with the fast growth in such medical conditions, although this has slowed down a little (2012: 43\%; 2006: 50\%). Of particular note is the rise in volume-related overload at constant overall professional overload between 2006 and 2018 (at 5\%). In 2018, 23\% of employees were overstretched in quantitative terms, while in 2016 in comparison, the value was still only at $17 \%$. Many employees feel unable to perform their duties to the best of their abilities. The high-stress levels overall ensue in particular from the high intensity of work. As the causes of this increase in intensity, for instance, multitasking $(60 \%)$, strong deadline or performance pressures $(48 \%)$, disruptions or interruptions at work (46\%), or fast work (34\%) are mentioned. Thus overall, 69\% of employees and $70 \%$ of managers have had at least one health-related complaint (Bundesanstalt für Arbeitsschutz und Arbeitsmedizin, 2020). The "DGB-Index Gute Arbeit" (2019) confirms these results and concludes that employees $(80 \%)$ feel exposed to high stresses due to insufficient personnel resources. The study also indicates other factors of the growing workload (57\%). The bulk of the complaints concerned poor appreciation by superiors (none for 7\% and very low for 23\%). Many of these mental stresses were overshadowed by physical stresses such as an enforced non-physiological body posture at work, which $51 \%$ of the employees claimed.

The impacts of these stresses shape the results of the health report of the German company health insurance funds. The report points out this exacerbating trend and concludes that

- the incidence of mental conditions among employees has increased disproportionally as compared to other occupational illnesses over the last years;

- a high proportion of days of absence due to sickness is attributable to mental illnesses;

- a half of the mental conditions directly relate to the behaviour of the management (TK 2020; Knieps \& Pfaff 2020).

Not least and in particular, the German Ordinance on Industrial Health and Safety (BetrSichV) in its current version (2019) imposes in this regard obligations specifically on corporate management and demands consequent focus on the hazards posed by mental stresses and the risks faced by the reporting employees, and that protective measures be taken so as to mitigate the health risks for the employees. But frequently, managers also are the cause of stresses and disruptions in the work environment. Their behaviour has a sustained effect on the mood in the team, and a bad disposition makes them ill (Janssen $\&$ Neuber 2008). For managers, this means that appreciation, recognition, and praise are not optional 
but an essential part of their job. This is because they are the key contributing factor so that employees can feel well at work (Struhs-Wehr, 2017). Also promotive to that is trust. This has been confirmed by the results of a study by the German Economic Institute (IW, 2018). Accordingly, trust is an important factor in wellbeing. The key prerequisite for that is the management's appreciative and trustworthy behaviour (Enste et al., 2018). Thus where a company opts for an approach with less supervision, about 60 percent of the workforce, according to a study, are highly satisfied with their work. The stronger supervision, the lower this figure: in firms with a strong supervision culture, only about 45 percent of employees are satisfied (IW, 2018). Badura et al. (2018) conclude in the 2018 report on absence times that employees who are exposed to a bad mood in their enterprise are less satisfied with their own health and are also sick more often. On this account, a poorly viewed atmosphere in the company goes along for 27.5 percent of the respondents with dissatisfaction about their health. This share is three times that of the comparison group that views the atmosphere in the company favourably (8.9 percent).

This means that a positive corporate culture is of key importance (Badura \& Walter 2014). Aspects of corporate culture include leadership style, focus on the workforce, and fairness in compensation. According to the conclusions of a study, employees who are experiencing a bad mood in their company suffer more often from physical and mental conditions (Badura et al., 2020). Corporate culture thus determines the work atmosphere and has a sustained effect on the number of workers on sick leave, onthe-job performance, job satisfaction, perceived stress at work, and motivation. The continued success of a company hence can only be ensured if

- the managers are professionally competent and personally suitable for the tasks they are assigned, and control the relations with their reporting staff accordingly;

- the instrumental and social relations in the team function adequately well;

- there is a widely accepted corporate culture that effectively aligns professional activities, preferably of all the participants, with corporate goals.

Under this systemic approach, what matters are the interactions between leadership and execution, the structural and instrumental conditions in an organisation and the strategic alignment of corporate culture as comprised, for instance, in key corporate objectives. These areas must be integrated and coordinated with each other, and the present investigation aims at these system components.

\section{Data and methodology}

For purposes of this study, the methodology of qualitative social research has been chosen. The qualitative method is the preferable choice for this examination as it exposes social reality and shows how respondents view and experience their world (Flick, 2017; Merriam, 2009). A total of 76 experts were surveyed, thereof 25 experts from commercial enterprises and 51 experts from the public sector. Of the 25 experts with commercial enterprises, 18 were from medium-sized companies with a workforce of above 1,000 employees, plus seven with professional associations. The experts from the public sector were from communal services (13), regional administrations (14), internal security (21), and three from professional associations. The experts worked in different dedicated units and departments. These included functions in charge of occupational health and safety, others were with human resources departments, managers at the top and mid-management levels, management representatives for equal treatment, and members of staff councils and work councils. All the experts were subjected to a structured interview that was conducted over the phone and took about 60 minutes. In the lead-up to the interviews, there was a briefing with the participants. In further course of the examination, the interviews were complemented by document analysis. This analysis focused on the schedules of responsibilities, guidelines of corporate culture, leadership tools such as the annual interview, assessment forms, reports from hazard analyses, employee surveys, and job descriptions (primary documents). As secondary documents, instructions, and notifications to staff were referred to. In selecting the documents and surveying the experts, a strictly limited and subjective focus included an explorative approach and a clear delimitation and definition of the examination scope. The interviewer had familiarised herself in the lead-up to the survey with pertinent documents. Not always, the interview partners were helpful in providing the documents prior to the survey. This was often due to a lack of awareness of the experts about the relevant documents being available in the company. 


\section{Results}

Commercial enterprises and the public sector both emphasise the importance and necessity of health prevention. In contrast with the original assumption, this commitment in both the spheres is fed mainly by the imperative of a generally recognised corporate social responsibility and care for the reporting staff. Differences on a continuous scale occur as regards the specific implementation. For instance, the importance of health prevention in the public sector has been outlined in particularly clear terms by pointing out the need for a more effective reduction of absences due to sickness, while the commercial sphere mainly talks about healthy work in a healthy work environment. While in commercial enterprises, the perspective on this topic was generally shared across the board, in the public sector, things were more varied. Commitment to health prevention was particularly strong in public security, followed at some distance by communal services. In comparison, at the level of regional authorities, there was much less commitment. The experts explained this by pointing the office jobs that almost exclusively prevail in this particular area.

The continuity of the range of conditions found in the commercial and public sectors also showed in the structural prerequisites for health prevention. In commercial enterprises, the fields of occupational safety and corporate performance mostly were by the statements of the experts well interconnected and, also by the expert accounts, sufficiently budgeted as well. The company management was receptive to and showed interest in the topics of prevention, and it was proactive in a number of ways. The high priority of health prevention also showed, as was verified in the document analysis, incorporate guidelines and the strategic alignment of corporate objectives. In many dedicated areas of the surveyed companies, the advances, actions, and results in health prevention were emphasised in a particularly pronounced way. In contrast, the experts from the public sector felt less interconnected. They frequently had to take with their health prevention-related concerns and initiatives a difficult path through the official channels and did not feel these concerns having been treated with due priority. In the few public administrations the management in which showed a degree of understanding for these topics, the concerns were heeded and swift actions implemented. All the experts nevertheless agreed in that in recent years there has been a general shift towards a stronger emphasis on health prevention in organisations.

However, many experts from the public sector complained about the lack of a systemic approach. The at times large numbers of individual actions in preventive healthcare lacked a consistent focus and were typically driven by singular interests and initiatives, such as of the equal treatment representatives, the staff council or the safety representative, with unclear connectedness to an overall concept. In contrast, the experts from commercial companies confirmed a more concise and strategically aligned approach. A central supervisor/contact function controlled this coordinated strategic line, mostly appointed as a staff unit directly to the management unit concerned. The function reported about progress directly to the management.

As the core component, all the experts deemed the need for a systematic hazard assessment. All the experts surveyed emphasised the importance of statutory regulations, which would make their work easier. They were convinced that mental health prevention in white-collar jobs and the services sector needed to be more strongly emphasised and implemented more consequently as a design principle in corporate management and corporate policies in their companies. In the executive commercial sphere, this was the subject of performed job analyses with the involvement of own and external experts. The managers in this sphere knew the challenges, showed understanding of them, and, in particular, were competent to deal with industrial safety issues. Human resources development was aligned with a focus on this topic in mind. At critical events, expert teams were appointed in time that systematically addressed applicable issues in project groups. In the public sector, comparable approaches can be found to some extent in fields such as building yards, urban park and greenery management, civil construction authorities, or fire departments. In such organisations, competence in health prevention was consequently promoted and required also and mainly at the lower and mid-management levels.

In accounting for and interpreting psychological stress factors, the commercial sphere and the public sector differ mainly in their conclusions, implementation of these, and continuous further development (Kretzer 2015). Of the 17 companies surveyed, ten had used questionnaires in representative sections of office jobs or throughout, while of the 32 public administrations included in the survey, this tool was only used by 14 . Two public administrations and three commercial enterprises already had conducted in the continued use of this tool follow-up hazard assessments at 2- or 3-year intervals. 
As for the critical comments on the procedure and interpretations under the method used herein were similar from both the experts with commercial enterprises and the public sector. They concerned, for instance, the periods of time from collecting the data through assessment until result notification, being criticised for far too long. Mostly between the data collection and publication of the results, there were intervals of over seven months, and in several instances, almost up to one year. The experts reported unanimously that this was what most of them found as the survey participants discouraging. Also, the low level of participation was complained about that varied between the organisations on a wide scale from approx. $30 \%$ to almost $70 \%$. Within the organisations as well, there were substantial differences in participation in the survey. In some organisational units, almost the entire workforce participated while only one fifth or one sixth of staff in others. Because for evaluation per organisational unit, a minimum participation of four to six persons was envisaged, in some instances, several administrative units were grouped together in the evaluation. The result of this are almost invariably non-specific statements. Many experts ascribed the low level of participation to poor contracting and priming of the respondents in the run-up to the survey. Many open questions thus remained unanswered. Moreover, data protection regulations and anonymity provisions stoked fears resulting from many not taking the questions. On the other hand, as was found by the accounts of the experts, participation was much higher in organisations in which the management in the lead-up to the survey laid out its rationale to the staff for example in team meetings not least also in order to explore the significance of the survey to the team. To sum up, it can be concluded that

1. The presumed differences between commercial enterprises and the public administration have not been confirmed in the interviews. The progress status towards health prevention in commercial enterprises and the public sector is at a comparable level. In both the sectors, the variance between and within the explored organisations is larger than in a summary comparison between commercial enterprises and the public sector.

2. Both in commercial enterprises and the public sector, there are many inspiring applications that facilitate learning from the best and for which no clear-cut dividing line can be drawn between 'typical public sector' and 'typical commercial enterprises'.

3. The aim of health prevention is stated more clearly in public administration by pointing out a better reduction of absences due to sickness, while the commercial sector mostly claimed as aim healthy work in a healthy environment. Neither of these justifications were expected as such.

4. It was promotive to health prevention when there was a corporate strategy with such focus and its aims clearly defined, declared, and communicated in corporate culture and respective guidelines.

5. There was a convincing and high-level health prevention always where there was direct access to management, for instance, through organisational functions such as a staff unit, a central coordination group and/or a project group.

6. Organisations that paid particular attention to the psychological hazard assessment also exhibited a variety of actions beyond the actual immediate workplace environment (such as flexible working hours, reconciling job and family).

7. There was tendentially a high degree of participation in a psychological hazard assessment where the management explicitly subscribed to and expressed its clear support for the survey.

8. There was also a high degree of participation in the surveys on hazard assessment where the staff councils and dedicated departments closely coordinated with each other and acted towards external parties in unison through joint actions and measures carried by both the staff councils/work councils and the respective dedicated departments.

9. Not helpful were the excessive periods of time between data collection through evaluation until the publication of the results. As a result, the individual sense of connection between the survey and its results were partly lost.

10. By accounts of the experts, many employees resent the lack of appropriate follow-up measures and actions to the survey. Many participants did not see any improvements in their particular situation in the wake of the evaluation of the survey results. Frequently because of that, a disparity is claimed between the effort invested and any resulting benefits for the individual. 
11. There are significant differences between managers in how they laid out the rationale of the survey to staff and how the results were explored and processed in the team. At a high level of commitment of the direct managers, the team members' opinions were much more favourable.

\section{Discussion}

Many of the experts surveyed see unresolved methodological issues in the implementation of the psychological hazard assessment and interpretation of its results. According to such opinions, health prevention in environments with psychological stresses cannot end at an organisation's entry and exit points (Hahnzog, 2018; Bäcker \& Hillert, 2018). The surveys on the hazard assessment, though, remain restricted to this interval. In contrast the scope of the topics explored does not include the private situation burdens and individual strains that can have a pronounced impact on subjective health. In that sense, a psychological hazard assessment that remains restricted to the work environment is by its very definition incomplete. Empirical experience shows that hazardous exposures from the private sphere can superimpose work-related stresses. In that sense, the design factors 9 and 10 exceed in importance the other ten hazard areas (Bundesanstalt für Arbeitsschutz und Arbeitsmedizin, 2021). Despite these methodological limitations, the hazard assessment for psychological stresses is deemed an opportunity by the experts both for the workforce and the enterprise. The opportunity has been used in practical applications mainly in areas where the professional and the private spheres overlap, for instance, with programms such as "Reconciling Job and Family", in working hour policies, or incorporate social initiatives. To what extent, though, and in which of their components such programmes have or will have an effect on the general subjective health is not yet foreseeable. Although the responses to the questions about the employer's appeal imply that these have been viewed positively, a more exact analysis of the effects of these initiatives would be indeed helpful for health management in order to be able to define and implement key focus points for health policies in a more targeted manner.

Consequently, it needs to be verified whether and to what extent the question sets can reveal the effects and effectiveness of individual actions taken. This is because the psychological hazard analysis as part of a more comprehensive health management does not end with identifying the current status, meaning the aspects that need attention, but based on these results, targeted actions and measures to promote health must be planned budgeted, and executed. For that, there has to be the capacity to correctly assess the effects of corporate actions and measures as well as the limits of the exposures and stresses originating in the private sphere.

For that, however, it is necessary for the question set as the reference base for such decisions to measure and quantify what is meant to and expected from this tool. Presently there are no scientifically rigorous studies on this aspect. The participating experts complained that the providers of these surveying tools and their claims of reliability of the same often would not be put under sufficient scrutiny. In interpreting the data collected with these tools, it is suggested that these surveys are a tried and proven method with high diagnostic relevance. But a comparison of the question sets for hazard assessment presented herein makes this appear to be doubtful. For instance, by information from the experts, the physical scope already of such surveying tools varies between about 50 to 150 items. Compiling these items according to the experts is frequently contingent upon the commitment of dedicated departments and individuals. External providers offer a basic range of questions that the customer can expand. However, the outcome of the process is that there are frequently overlaps in scope and imprecise or ambiguously worded questions. Also, oftentimes, the scaling is not adjusted for the particular questions asked. But the quality criteria in this surveying method and how reliable the collected data are is of key importance for the strategic alignment of the organisation and for planning targeted measures. The question of the reliability of the statements and interpretations arises concerning the surveying tool and the extent of participation in the survey. The experts report the levels of participation in range from 30 to about 60 percent. In that, there are substantial differences even between organisational units within one and the same organisation. The experts accept these differences in the degree of participation as is and not systematically scrutinised and weighted relative to the survey results. Thus different organisational units may be lumped together that, for instance, may have different team leaders. Both team leaders then obtain team-specific information from the aggregated data on their team behaviour, which may refer to either of them and their possibly different leadership styles.

In contrast to tried and tested diagnostic test procedures, these surveying tools are at best capable of delivering a range of opinions. It is unclear, though, how reliable these results are as a reference base 
for the strategic alignment of an organisation. The reliability of this range of opinions improves where the question set is designed to standard quality criteria such as impartiality, reliability (measurement accuracy), validity, scaling, standardisation, economy, usefulness, reasonableness, integrity and acceptance, fairness (Kubinger, 2019; Klapprott \& Buchinger, 2018). An improvement in reliability of the psychological hazard assessment can be expected where these quality standards are applied more consequently in compiling the questionnaire, selecting the items, in priming for the survey, and in the evaluation of the data and interpretation of the survey results.

In this regard, the experts claim in the interviews, for instance, that psychological hazard assessments necessitate meticulous and comprehensive preparations already in the run-up to the survey. Where the team leaders duly laid out the rationale of the survey to the team, the survey participants approached the questions more conscientiously and in a more focused manner. Critical events with a negative impact on the further course of the survey and implementation occurred sporadically in the design phase, the actual survey phase, or the evaluation base.

Designing is about the quality standards to observe, such as the detailed specification and delimitation of topics, as well as clarification of formal aspects concerning the course of the procedure such as confidentiality of data, the survey scope, the level of detail in the assessment, and scaled access to data according to organisational units. As regards scope, mutual coordination is due between the management board and the coordinating functions (such as the representatives for occupational safety and equal treatment, staff council, human resources development, and selected dedicated units) in choosing the items for and scope of the questionnaire. Concerning this, it was important to the experts that the question sets need to be adjusted to the particularities of administration of the company concerned.

For and during the actual survey phase, the small details shaped the level of participation and involvement in the survey. These give rise to additional quality standards: there should be non-disturbed, direct, and encrypted access to the Internet available. Where such access is not possible, the survey must be performed via print questionnaires. Such issues need to be clarified with sufficient advance as opposed to just before the survey. For this, it is recommended to involve the team leaders early on. The tried and tested tools for this purpose have been workshops in the lead-up to the survey, in which the scope and course of the survey are explored. An expert reported on the optimum approach of arranging meetings with the respective managers in charge, which reached in a top-down manner all vertical tiers in the hierarchy and horizontally all the teams. As the survey's success is contingent on the extent of participation of staff, it is key to ensure a high level of transparency and individual commitment. The principle applies here: "Use people who are helpful contributors in the planning, help design the course and accept a share of the responsibilities." This is because in the hazard analysis as well as in designing the work environment, all staff members have to contribute their share by actively supporting the process. In order to allay fears and reservations, all the survey participants should be kept up-to-date on all steps in the course of the procedure via internal notifications and web-based information events. Another important quality criterion refers to the involvement of direct managers. Commitment by the management is a vital prerequisite for a high level of participation of staff and for an open and fair approach to the questions. This may succeed where the managers familiarise their teams in the lead-up to the survey in an active manner (such as in team meetings) with its concept and goals and credibly and competently promote the aims of the hazard analysis.

The evaluation and interpretation phase should follow preferably soon after the data have been collected. A prerequisite for this is comprehensive preparatory work in organisational terms. As the data evaluation was performed via frequency analysis, these evaluation steps can be defined already in advance of the survey. This also applies where individual items are comprised into clusters. Alongside a summary evaluation, depending on the extent of participation, there is a breakdown of the results by the different organisational and dedicated units down to the level of teams.

The key for sustained and continuous further development is exploring and processing the results in the team. In this processing, quality criteria apply, such as those comprised in the eight-stage model.

1. Stage: Priming and preparing the team for the psychological hazard analysis in a joint team meeting. Such meetings have proven useful tools for similar issues (e.g., Meixner \& Meixner, $2019 b$ ). The respective fears and expectations are explored in such meetings, the course of the procedure outlined, and pertinent rules agreed. 
The purpose of this warming-up phase is to proactively address any reservations and resistances so as to increase the level of participation in the hazard analysis. With this timely information and interaction within the team, internal communication is directed towards the factual aims, and thus the emotional biases arising out of uncertainty are countered.

2. Stage: The questionnaire items are explored, specified, and mutually agreed on in an another team meeting. This is about weighting the individual topics, specifying the detailed scope of the items, and the aspects of scaling.

The purpose of this phase is that preferably as many team members as possible interpret the items in the same way, and thus a common basis for the evaluation can be expected.

3. Stage: At the start of and during the actual survey phase, the direct manager encourages the team in a suitable form to duly and prudently use the opportunities arising from the survey. Contact partners from within the team or from a central corporate contact unit, as applicable, provide support to the team members with general and organisational questions.

This phase aims to explicate the significance of the hazard assessment to the team and to one's own interests. Active involvement is encouraged and thus also the aims and weight of the survey communicated.

4. Stage: After completion of the actual survey phase, there is an exchange of experience and of any improvement suggestions concerning the course of the survey in terms of scope and its organisational aspects, and the scope, course and organisational aspects are evaluated and documented for continuous improvement purposes.

The purpose of this phase is to secure the insights from the course of the survey and use the experience gained for follow-up analyses. Another effect is that all the participants remain involved in follow-up actions and that the discussion within the team and between teams does not lose its focus.

5. Stage: After the central summary evaluation of the hazard assessment and presentation of the report, the workforce at the respective levels in the hierarchy is informed in a top-down process, the results are interpreted at each vertical level concerned and the resulting items to focus on in interactions as well as pertinent short-term, medium-term and long-term health prevention measures identified (see also Hoopes, 2003).

The purpose and intention of this phase are to extract from the summary result the particularities of the organisational reporting units with their respective strengths and support needs. In this way, the necessary actions and measures can be assigned priorities in a comprehensive concept.

6. Stage: In a counterflow procedure, the hazard assessment results are discussed and interpreted in the team, with follow-up in the form of specific measures to improve the work situation. In this group discussion, the design factors and the determinants are differentiated. While the determinants have to be accepted as is by the team members, the design factors can be shaped. The team compiles a priority list of short-term, medium-term, and long-term actions based on this discussion. It is determined who can how to contribute to improving the work environment. In the process, also the expectations are noted towards direct managers and/or units the staff is reporting to. These expectations are implemented in the hierarchy in a bottom-up process. Through this consequent distinction between determinants and design factors, stressors can be effectively addressed. In these team discussions, the involvement is recommended of an external or internal "host" (Meixner \& Meixner, 2019a). This approach's rationale is to ease the burden of the discussion on the team manager, as many items concern the management and its leadership style. In order to be able to focus on this feedback, the team manager in addressing these issues should be exempted from the discussion hosting tasks (Meixner \& Meixner, 2019b). The purpose of this phase is to align the particularities of the organisational units with the perspective of the functions these report to and to work towards a common view and assessment.

7. Stage: From the alignment of the top-down interpretations and conclusions as well as improvement suggestions coming in the bottom-up direction, the short-term, medium-term, and long-term goals are operationalised and responsibilities within the team and above defined for the individual areas of actions. As the objective workload results in individually specific challenges, this is not just about defining team-specific change processes, but talks are also necessary regarding specific clusters of topics of the survey below the team level in small groups 
down to talks with individual team members. For this, annual interviews or other forms of communication can be used between the managers and the team members.

The aim is to work towards improvements in the team's workload by exploring options regarding the process flows and the work environment and, at the same time to reduce individual strains. For that, the team discussion is followed by support to individuals with the aim to affect individual-specific stressors in a positive direction.

8. Stage: In prescheduled milestone talks, the team and the team members monitor progress and developments and adjust the planned and agreed actions for health prevention at the team level as needed. This lays the ground for the next hazard assessment in the regular cycle.

The purpose of this phase is to let all the persons involved experience the hazard assessment as a continuous process and to make progress palpable and make the people feel they are part of it. This is in line with the principles of change management (Friedrich \& Gold, 2018).

\section{Conclusion}

It has been shown in this study that sustained and effective health prevention may only fully succeed where the management and operative managers are more consistently involved with its aims. In the first step, the structural prerequisites for health prevention need to be established in the organisational structure, process flows, and budgeting. In order for the managers to be able to identify with these initiatives and promote these accordingly as vital aspects in the team, the corporate culture needs to be aligned with these objectives. This includes a compatible design of the leadership systems such as the annual interview, assessment of potential or stimuli in terms of how bonuses are designed, and comprehensive training schemes and healthcare initiatives. Particular attention in the process must be paid to the psychological hazard assessment. Alongside the current status of risks and hazards identified through the questionnaire items, with the aid of these results, a continuous improvement plan for the work environment is to be prepared in an interaction process between managers and their reporting employees. For that, an eight-stage model has been devised, which can be adjusted for relevance and practical viability in follow-up examinations of specific needs and used as a quality standard.

\section{References}

Antonovsky, A. (1993). Gesundheitsförderung versus Krankheitsforschung [Health promotion versus disease research]. In: Franke, A.; Broda, M. (ed.). Psychosomatische Gesundheit Versuch einer Abkehr vom Pathogenese-Konzept [Psychosomatic Health Attempt to move away from the pathogenesis concept], Tübingen: dgvt, p. 3-14. ISBN 9783871591204.

Antonovsky, A. (1997). Salutogenese. Zur Entmystifizierung der Gesundheit [To demystify health]. German extended edition of Alexa Franke. Tübingen: dgvt. ISBN 9783871591365.

Arbeitsschutzgesetz (ArbSchG) [Occupational Health and Safety Act] from 7. August 1996 (Federal Law Gazette I S. 1246), which was last amended by Article 1 of the law of December 22, 2020 (Federal Law Gazette I S. 3334).

Arbeitssicherheitsgesetz (ASiG) [Occupational Safety Act]. Law on company doctors, safety engineers and other occupational safety specialists from 12. Dezember 1973, last amended by Article 226 of the Ordinance of 31. October 2006.

Bäcker, K.; Hillert, A. (2018). Wie misst und beurteilt man die Gefährung durch psychische Belastung am Arbeitsplatz? [How do you measure and assess the risk of mental stress in the workplace?]. In: Pfannstiel, M. A.; Mehlich, H. (eds.). BGM - Ein Erfolgsfaktor für Unternehmen. Lösungen, Beispiele, Handlungsanleitungen [BGM - a success factor for companies. Solutions, examples, instructions for action]. Wiesbaden: Springer Gabler, 2018, p. 699-714. ISBN 9783658227371. DOI 10.1007/978-3-658-22738-8.

Badura, B. (2017). Arbeit und Gesundheit im 21. Jahrhundert [Work and Health in the 21st Century]. In: Badura, B. (ed.). Arbeit und Gesundheit im 21. Jahrhundert. Mitarbeiterbindung durch Kulturentwicklung [Work and Health in the 21st Century. Employee loyalty through cultural development]. Berlin: Springer Gabler, p. 1-17. ISBN 9783662531990. DOI 10.1007/978-3-662-53200-3

Badura, B.; Ducki, A.; Schröder, H.; Klose, J.; Meyer, M. (eds.) (2018). Fehlzeiten-Report 2018: Sinnerleben im Beruf wirkt sich auf Gesundheit aus [Absence Report 2018: Meaningful life at work affects health]. Berlin, Heidelberg: Springer. ISBN 9783662573877. DOI 10.1007/978-3-662-57388-4.

Badura, B.; Ducki, A.; Schröder, H.; Klose, J.; Meyer, M. (eds.). Fehlzeiten-Report 2020. Gerechtigkeit und Gesundheit [Absence Report 2020. Justice and Health]. Wiesbaden: Springer. ISBN 9783662615232. DOI 10.1007/978-3-662-61524-9

Badura, B.; Walter, U. (2014). Führungskultur auf dem Prüfstand [Leadership culture put to the test]. In: Badura, B.; Ducki, A.; Schröder, H.; Klose, J.; Meyer, M. (Hrsg.). Fehlzeiten-Report 2014. Erfolgreiche Unternehmen von morgen - gesunde Zukunft heute gestalten [Absence Report 2014. Successful companies of tomorrow - shaping a healthy future today]. Berlin, Heidelberg: Springer, p. 159-162. ISBN 9783662435304. DOI 10.1007/978-3-662-43531-1.

Berg, K. (2019). So gelingt der Schritt zurück ins Team [This is how you can step back into the team]. Retrieved March 18, 2021, from https://www.arbeitsfaehig.com/uploads/z-neue\%20Uploads/Literatur/BEM/So\%20gelingt\%20der\%20Schritt\% 20zur\%C3\%BCck\%20ins\%20Team_Berg.pdf 
Betriebssicherheitsverordnung (BetrSichV) [Industrial Safety Ordinance] of February 3, 2015 (Federal Law Gazette I p. 49), which was last amended by Article 1 of the Ordinance of April 30, 2019 (Federal Law Gazette I p. 554).

Bundesanstalt für Arbeitsschutz und Arbeitsmedizin [Federal Institute for Occupational Safety and Health] (2021). Handbuch Gefährdungsbeurteilung [Risk assessment manual]. Published by M. Kittelmann, L. Adolph, A. Michel, R. Packroff, M. Schütte, S. Sommer. Dortmund: Self-published. DOI 10.21934/baua:fachbuch20210127

Bundesanstalt für Arbeitsschutz und Arbeitsmedizin [Federal Institute for Occupational Safety and Health] (2020). Stressreport Deutschland 2019. Psychische Anforderungen, Ressourcen und Befinden [Stress Report Germany 2019. Psychological demands, resources and well-being]. Dortmund: Self-published. ISBN 9783882612592. DOI 10.21934/baua:bericht20191007.

DGB-Index Gute Arbeit [DGB index Good Job] (2019). Alle gesund? Wie die Beschäftigten ihre Arbeitsbedingungen und ihren Gesundheitszustand bewerten [How the employees rate their working conditions and their state of health]. Special evaluation of the representative survey on the DGB index Gute Arbeit 2019, Berlin: Self-published.

DIN EN ISO 26800:2011. Ergonomie - Genereller Ansatz, Prinzipien und Konzepte [Ergonomics - General approach, principles and concepts]. DOI 10.31030/1775247.

DIN EN ISO ISO 6385:2004. Grundsätze der Ergonomie für die Gestaltung von Arbeitssystemen [Principles of ergonomics for the design of work systems]. DOI 10.31030/2429191.

Enste, D.; Grunewald, M.; Kürten, L. (2018). Vertrauen ist gut, Kontrolle ist schlechter [Trust is good, control is worse]. Press release IW Cologne 10.07.2018, retrieved March 18, 2021, from https://www.iwkoeln.de/presse/pressemitteilungen/ beitrag/dominik-h-enste-louisa-marie-kuerten-vertrauen-ist-gut-kontrolle-ist-schlechter.html

Flick, U. (2017). Qualitative Sozialforschung. Eine Einführung [Qualitative social research. An introduction]. 8th completely revised new edition. Reinbeck near by Hamburg: Rowohlt. ISBN 9783499556944.

Friedrich, M.; Gold, T. (2018). Herausforderung Status quo - von der Ist-Analyse zu den Maßnahmen eines Betrieblichen Gesundheitsmanagements [Challenge of the status quo - from the analysis of the current situation to the measures of a company health management]. In: Pfannstiel, M. A.; Mehlich, H. (eds.). BGM - Ein Erfolgsfaktor für Unternehmen. Lösungen, Beispiele, Handlungsanleitungen [BGM - a success factor for companies. Solutions, examples, instructions for action]. Wiesbaden: Springer Gabler, p. 631-680. ISBN 9783658227371. DOI 10.1007/978-3-658-22738-8.

Ghadiri, A.; Peters, T. (2020). Betriebliches Gesundheitsmanagement in digitalen Zeiten [Corporate health management in digital times]. Wiesbaden: Springer Gabler. ISBN 978-3-658-32430-8. DOI 10.1007/978-3-658-32431-5

Giesert, M.; Liebrich, A.; Reuter, T. (2016). Das Handlungsfeld Betriebliches Eingliederungsmanagement im Betrieblichen Gesundheitsmanagement - Erfahrungen und Ergebnisse aus Forschung und Praxis [The operational integration management field of activity in operational health management - experience and results from research and practice.]. In: Pfannstiel, M.A.; Mehlich, H. (eds.). Betriebliches Gesundheitsmanagement. Konzepte, Maßnahmen, Evaluation [Corporate Health Management. Concepts, measures, evaluation]. Wiesbaden: Springer Gabler, p. 267-277.

Hahnzog, S. (2018). Gesund und glücklich arbeiten - Gefährdungsbeurteilung psychischer Arbeitsbelastung [Working healthily and happily - risk assessment of mental workload]. In: Pfannstiel, M. A.; Mehlich, H. (eds.). BGM - Ein Erfolgsfaktor für Unternehmen. Lösungen, Beispiele, Handlungsanleitungen [BGM - a success factor for companies. Solutions, examples, instructions for action]. Wiesbaden: Springer Gabler, 2018, p. 681-698. ISBN 9783658227371. DOI 10.1007/978-3-658-22738-8.

Hardering, F. (2020). Sinn in der Arbeit. Überblick über Grundbegriffe und aktuelle Debatten [Meaning in work. Overview of basic concepts and current debates]. Wiesbaden: Springer VS. ISBN 9783658308155. DOI 10.1007/978-3-658-30816-2.

Homberg, P. (2016). Auf- und Ausbau von Resilienz und Gesundheitskompetenz - Motivation zu mehr Gesundheit für Führungskräfte und Mitarbeiter/innen [Development and expansion of resilience and health literacy - motivation for better health for managers and employees]. In: Pfannstiel, M. A.; Mehlich, H. Betriebliches Gesundheitsmanagement. Konzepte, Maßnahmen, Evaluation [Corporate Health Management. Concepts, measures, evaluation]. Wiesbaden: Springer Gabler, $p$. 191-211. ISBN 9783658115807. DOI 10.1007/978-3-658-11581-4.

Initiative Gesundheit und Arbeit [Health and Work Initiative] (2015). iga.Report 29, Führungskräfte sensibilisieren und Gesundheit fördern - Ergebnisse aus dem Projekt ,,iga.Radar" [iga.Report 29, sensitizing managers and promoting health results from the "iga.Radar" project]. Retrieved March 18, 2021, from http://www.iga-info.de/fileadmin/redakteur/ Veroeffentlichungen/iga_Reporte/Dokumente/iga-Report_29_Fuehrungskraefte_sensibilisieren_Gesundheit_foerdern.pdf Insitut für Betriebliche Gesundheitsberatung (IFBG) [Institute for Workplace Health Counseling] (2000). \#whatsnext2020 Erfolgsfaktoren für gesundes Arbeiten in der digitalen Arbeitswelt [Success factors for healthy work in the digital world of work]. In cooperation with Techniker Krankenkasse, Haufe Akademie. Retrieved March 18, 2021, from https://www.ifbg.eu/fileadmin/aktuelles/Studienband_whatsnext2020-final.pdf

Institut der deutschen Wirtschaft Köln e. V. (IW) [Institute of the German Economy Cologne] (2018) IW-Trends 2/2018 Vertrauenskultur als Wettbewerbsvorteil in digitalen Zeiten [IW Trends 2/2018 Culture of trust as a competitive advantage in the digital age]. Editors: D. Enste, M. Grunewald, L. Kürten, Cologne: Self-published.

Janssen G.; Neuber V. (2008). Betriebssicherheits-Management nach BetrSichV, ein Leitfaden zur Umsetzung der Betriebssicherheitsverordnung (BetrSichV) in den einzelnen Unternehmensbereichen [Industrial safety management according to BetrSichV, a guideline for the implementation of the Industrial Safety Ordinance (BetrSichV) in the individual company areas]. Landsberg: ecomed, 2nd edition. ISBN 9783609663456.

Klapprott, F.; Buchinger, L. (2018). Die Gefährdungsbeurteilung psychischer Belastung als Fundament eines strategischen Betrieblichen Gesundheitsmanagements [The risk assessment of psychological stress as the foundation of strategic corporate 
health management]. In: Pfannstiel, M. A.; Mehlich, H. (eds.). BGM - Ein Erfolgsfaktor für Unternehmen. Lösungen, Beispiele, Handlungsanleitungen [BGM - a success factor for companies. Solutions, examples, instructions for action]. Wiesbaden: Springer Gabler, p. 715-738. ISBN 9783658227371. DOI 10.1007/978-3-658-22738-8

Kleinöder, N.; Müller, S.; Uhl, K. (2019). Die Humanisierung des Arbeislebens. Einführung und methodische Überlegungen [The humanization of working life. Introduction and methodological considerations]. In: Kleinöder, N.; Müller, S.; Uhl, K. »Humanisierung der Arbeit«: Aufbrüche und Konflikte in der rationalisierten Arbeitswelt des 20. Jahrhunderts [»Humanization of Work «: New beginnings and conflicts in the rationalized world of work of the 20th century]. Bielefeld: transcript, p. 9-32. ISBN 9783837646536. DOI 10.14361/9783839446539.

Kloimüller, I. (2016). Erhalt von Arbeitsfähigkeit als wesentliche Aufgabe im Betrieblichen Gesundheitsmanagement. In: Pfannstiel, M. A.; Mehlich, H. Betriebliches Gesundheitsmanagement. Konzepte, Maßnahmen, Evaluation [Corporate Health Management. Concepts, measures, evaluation]. Wiesbaden: Springer Gabler, p. 191-211. ISBN 9783658115807. DOI 10.1007/978-3-658-11581-4.

Knieps, F.; Pfaff, H. (eds.) (2020). Mobilität - Arbeit - Gesundheit. BKK Gesundheitsreport 2020 [Mobility - work - health. BKK health report 2020]. BKK Umbrella organization. Berlin: Medizinisch Wissenschaftliche Verlagsgesellschaft. ISBN 9783954665594.

Kretzer, M. G. (2015). Betriebliches Gesundheitsmanagement trifft öffentliche Verwaltungskultur [Corporate health management meets public administrative culture]. Norderstedt: Books on Demand. ISBN 9783739274515.

Kubinger, K. (2019). Psychologische Diagnostik: Theorie und Praxis psychologischen Diagnostizierens [Psychological diagnosis: theory and practice of psychological diagnosis]. 3r r reworked edition. Göttingen: Hogrefe. ISBN 9783801727796 Matyssek, A. K. (2012). Gesundheitsmanagement als Führungsaufgabe in der öffentlichen Verwaltung [Health management as a management task in public administration]. Bundesgesundheitsblatt, 55(2), p. 205-210.

McWilliams, A.; Rupp, D. E.; Stahl, G. K.; Siegel, D. S.; Waldman D. A. (1999). New Developments in the Study of Corporate Social Responsibility. In: McWilliams, A.; Rupp, D. E.; Siegel, D. S.; Stahl, G. K.; Waldman D. A. The Oxford Handbook of Corporate Social Responsibility: Psychological and Organizational Perspectives. Oxford: Oxford University Press, p. 3-19. ISBN: 9780198802280. DOI: 10.1093/oxfordhb/9780198802280.013.20.

Meixner, J.; Meixner, H.-E. (2019a). Führungsfeedback: Chance nutzen und sich der Herausforderung stellen [Management feedback: seize the opportunity and face the challenge]. DÖD, 2019(4), p. 81-88.

Meixner, J.; Meixner, H.-E. (2019b). Das Führungsfeedback gemeinsam organisieren - sich Zeit nehmen und sich Zeit geben für eine erfolgreiche Interaktion im Team [Organize management feedback together - take your time and give yourself time for successful team interaction]. DÖD, 2019(7/8), p. 157-165.

Merriam, S. B. (2009). Qualitative Research: A Guide to Design and Implementation. San Franzisco: John Wiley \& Sons. ISBN 9780470283547.

Neuner, R. (2019). Psychische Gesundheit bei der Arbeit. Gefährdungsbeurteilung und Betriebliches Gesundheitsmanagement [Mental health at work. Risk assessment and company health management]. 3rd updated edition. ISBN 9783658239602. DOI 10.1007/978-3-658-23961-9.

Pfaff, H.; Lindert, L. Zeike, S. (2020). Evidenzbasierte psychische Gefährdungsbeurteilung. Prinzipien und Instrumente für Entscheider in der betrieblichen Praxis [Evidence-based psychological risk assessment. Principles and instruments for decision-makers in operational practice]. Wiesbaden: Springer. ISBN 978-3-658-28066-6. DOI 10.1007/978-3-658-28067-3.

Reuter, T.; Laudel, R.; Liebrich, A.; Giesert, M. (2019). Arbeits- und Beschäftigungsfähigkeit systematisch wiederherstellen, erhalten und fördern. Ein Handlungsleitfaden für Unternehmen, betriebliche Interessenvertretungen und Beschäftigte [Systematically restore, maintain and promote work and employability. A guideline for companies, company interest groups and employees]. Bonn: MIT Institut Bonn.

Richter, A.; Geis, R. (2019). Betriebliches Eingliederungsmanagement: Fürsorgepflicht und Gesundheitsschutz im öffentlichen und kirchlichen Dienst [In-company integration management: duty of care and health protection in the public and church service]. 4th updated edition, Regensburg: Walhalla. ISBN 9783802951022.

Schmid E.; Pircher Verdorfer, A. (2020). Gerechtes Führen: Wie sich ethisches und destruktives Führungsverhalten auf die Mitarbeitenden auswirkt [Fair leadership: How ethical and destructive leadership behavior affects employees] In: Badura, B.; Ducki, A.; Schröder, H.; Klose, J.; Meyer, M. (Eds.). Fehlzeiten-Report 2020. Gerechtigkeit und Gesundheit [Absence Report 2020. Justice and Health]. Wiesbaden: Springer, p. 165-176. ISBN 9783662615232. DOI 10.1007/978-3-662-615249.

Simmel, M.; Graß1, W. (ed.) (2020). Betriebliches Gesundheitsmanagement mit System. Ein Praxisleitfaden für mittelständische Unternehmen [Systematic occupational health management. A practical guide for medium-sized companies]. Wiesbaden: Springer. ISBN 9783658269555.

Struhs-Wehr, K. (2017). Betriebliches Gesundheitsmanagement und Führung. Gesundheitsorientierte Führung als Erfolgsfaktor im BGM [Corporate health management and leadership. Health-oriented leadership as a success factor in Corporate Health Management]. Wiesbaden: Springer. ISBN 9783658142650. DOI 10.1007/978-3-658-14266-7

Techniker Krankenkasse (TK) (2020). Gesundheitsreport 2020 - Arbeitsunfähigkeiten [Health Report 2020 - Incapacity for work]. Retrieved March 18, 2021, from https://www.tk.de/resource/blob/2081662/ 6382c77f2ecb10cc0ae040de07c6807f/ gesundheitsreport-au-2020-data.pdf

Treier, M. (2019). Gefährdungsbeurteilung psychischer Belastungen. Begründung, Instrumente, Umsetzung [Risk assessment of psychological stress. Justification, instruments, implementation]. 2nd edition. Wiesbeden: Spinger. ISBN 9783658232924. DOI 10.1007/978-3-658-23293-1. 
Uhle, T.; Treier, M. (2019). Betriebliches Gesundheitsmanagement. Gesundheitsförderung in der Arbeitswelt - Mitarbeiter einbinden, Prozesse gestalten, Erfolge messen [Corporate Health Management. Health promotion in the world of work involve employees, design processes, measure success]. 4th edition. Wiesbaden: Springer. ISBN 9783662467244 . DOI 10.1007/978-3-662-46724-4.

Ulich, E.; Wülser, M. (2018). Gesundheitsmanagement in Unternehmen: Arbeitspsychologische Perspektiven [Health management in companies: occupational psychological perspectives]. 6th edition. Springer Gabler. ISBN 978-3-658-184346. DOI 10.1007/978-3-658-18435-3.

Wilrich T. (2015a). Praxisleitfaden Betriebssicherheitsverordnung: Verantwortlichkeit, Organisation, Pflichtenübertragung, Gefährdungsbeurteilung, Schutzmaßnahmen, Betriebsanweisung, Unterweisung, sichere Inbetriebnahme, Verwendung, Prüfung und Instandhaltung von Arbeitsmitteln nach dem Stand der Technik, mit 20 Gerichtsurteilen aus der Rechtsprechungspraxis [Practical guide to the operational safety regulation: responsibility, organization, transfer of duties, risk assessment, protective measures, operating instructions, instruction, safe commissioning, use, testing and maintenance of state-of-the-art work equipment, with 20 court judgments from legal practice]. VDE Series of publication. Volume 166, Berlin: VDE-Verlag.

Wilrich T. (2015b). Die Betriebssicherheitsverordnung 2015 - Überblick und Leitfaden für den Umgang in der Praxis [The Ordinance on Industrial Safety and Health 2015 - overview and guidelines for use in practice]. Der Betrieb (DB). 2015(17), p. 981-987.

World Health Organization (2005). Constitution of the World Health Organization. Retrieved March 18, 2021, from https://apps.who.int/gb/bd/PDF/bd47/EN/constitution-en.pdf?ua=1

ZFW (2016). Gesunde Führung [Healthy Leadership]. Study accompanying the Mindful Leadership Conference, on 8./9. April 2016 at the University of Witten / Herdecke, Witten: Self-published. 